\title{
Nuevos desafíos en tuberculosis
}

\author{
VICTORINO FARGA C.*
}

\section{New challenges in tuberculosis}

Tuberculosis (TB) is a main cause of disease and death in many countries of the world. The efforts to control this scourge have not been very successful. Even in Chile where we are near to reach the advanced stage of elimination of TB as a public health problem, five persons each week die of this disease. The main challenges for the control of TB and the most recent advances to counteract them are reviewed. A series of modern methods of diagnosis based on the techniques of molecular biology are reviewed. There is a need to develop procedures that can be applied in the so called "point of diagnosis", like the Xpert MTB/RIF test. There are new techniques for the diagnosis of latent TB infection (IGRA's), in order to identify infected subjects of high risk to develop disease to subject them to chemoprofilaxis. We need to develop shorter treatments for new cases and better drugs for multi-resistant patients. Ten new drugs have progressed into the clinical development pipeline for TB. New vaccines against tuberculosis are being investigated. Some of them are already being tried in the field. In the last years two new challenges have appeared: the association TB-AIDS, and the new epidemics of Multi Drug Resistant Tuberculosis (TB MDR and TB XDR). New techniques of diagnosis are described. Our main challenge is to make all this advances available for everybody. In Chile only the private sector has some of these techniques.

Key words: Tuberculosis, present situation, challenges, diagnosis, IGRA's, treatment, new drugs, new vaccines, Tuberculosis-AIDS, Multi Drug Resistant Tuberculosis.

\section{Resumen}

La tuberculosis (TBC) sigue siendo una de las principales causas de morbi-mortalidad en el mundo y los esfuerzos para controlarla han demostrado ser insuficientes. Aun en Chile, donde estamos cerca de alcanzar la etapa avanzada de su eliminación como problema de salud pública, fallecen 5 personas por semana de TBC. Este artículo presenta los principales desafíos de los Programas de Control de la TBC y los avances más recientes para enfrentarlos. Se analiza una serie de métodos de diagnóstico basados en técnicas de biología molecular. Se necesitan técnicas más sensibles que la baciloscopia que puedan ser empleadas en la periferia, en el llamado "punto del diagnóstico", como el test Xpert MTB/RIF. Están en estudio nuevos métodos de diagnóstico de la infección tuberculosa latente -los IGRA's - para identificar con mayor especificidad que con el PPD, a los infectados con alto riesgo de progresar a TBC para someterlos a quimioprofilaxis. Necesitamos tratamientos más breves para los casos nuevos, y drogas más eficaces para los enfermos de TBC multi-resistentes. Está en desarrollo la introducción de 10 nuevos medicamentos anti-TBC. Se necesitan vacunas más eficaces que la BCG, capaces no sólo de prevenir la infección, sino también de reforzar la inmunidad de los infectados y aún de los enfermos. Varias de estas vacunas se están ensayando en África. En los últimos decenios han aparecido dos nuevos desafíos: la asociación TBC-SIDA y las epidemias de TBC multi-resistentes (TB MDR y XDR). Se han desarrollado técnicas para identificar polimorfismos del gen rpo B, principal causa de resistencia a la rifampicina, considerada marcador de TB MDR. El principal desafío actual es poner todos estos avances al alcance de los que más los necesitan. En Chile sólo disponemos de algunas de estas nuevas técnicas, en su mayoría en clínicas privadas.

Palabras clave: Tuberculosis, situación actual, desafíos, diagnóstico, IGRA's, tratamiento, nuevas drogas, nuevas vacunas, Tuberculosis-SIDA, tuberculosis multi-resistentes.

+Basado en conferencia pronunciada en las Jornadas de Otoño 2011 de la Sociedad Chilena de Enfermedades Respiratorias.

* Profesor de Medicina de la Universidad de Chile. 
La tuberculosis no es aún una enfermedad derrotada, porque hay actualmente más de 10 millones de enfermos en el mundo, cada año se diagnostican más de 9 millones de casos nuevos, 1 a 2 millones de ellos mueren por esta enfermedad y, lo que es aún más importante, alrededor de un tercio de la población mundial, es decir alrededor de 2 mil millones de los habitantes de este planeta, están infectados por el Mycobacterium tuberculosis. Este enorme reservorio de portadores sanos de bacilos de Koch vivos, en fase latente, que pueden reactivarse en cualquier momento del futuro si disminuyen sus condiciones inmunitarias, permite asegurar que la tuberculosis acompañará a la especie humana, como problema de Salud Pública, hasta bien avanzado este siglo.

Durante los últimos decenios el mundo médico ha tomado conciencia de este precario escenario y ha estimulado toda clase de investigaciones y Programas de Control. Por ejemplo la OMS ha propuesto la estrategia STOP TB (Detenga la tuberculosis), que en esencia ha planteado las siguientes metas a nivel mundial:

- Detectar por lo menos el 70\% de los casos bacilíferos y curar por lo menos el 85\% de ellos para el año 2005. (Esta meta ya no se alcanzó ni en 2005, ni en 2010).

- Reducir las muertes por tuberculosis en un 50\% en el año 2015 respecto a las ocurridas el año 1990.

- Eliminar la tuberculosis como Problema de Salud Pública el año 2050.

Por su parte la Organización de Naciones Unidas dentro de la Meta 6 del Millenium Development plantea un objetivo mucho más modesto: Detener y empezar a revertir la incidencia de la tuberculosis en el mundo hacia el año 2015.

A pesar de tantos esfuerzos, la situación actual a nivel mundial es insatisfactoria, aunque en los últimos años el número de casos nuevos per cápita ha empezado a disminuir globalmente y se espera que antes del año 2015 cuatro regiones del mundo, cumplan la meta de alcanzar la mitad de la prevalencia y mortalidad que tenían en 1990. Sin embargo, se estima que dos regiones, África y Europa, no lo lograrán. No sólo los países de la antigua esfera soviética sufren una epidemia de tuberculosis y de tuberculosis multiresistente inesperada; varias ciudades europeas, como Londres, han visto aumentar año a año la incidencia de casos nuevos de esta enfermedad, en este caso por el efecto de las migraciones. Podemos apreciar lo difícil que va a resultar la eliminación de la tuberculosis aún en los países más desarrollados.

En Chile la situación de la tuberculosis durante la primera mitad del siglo XX era terrible. Entre 250 y 300 personas por 100.000 habitantes fallecían cada año de esta enfermedad. En realidad la tuberculosis fue durante mucho tiempo la principal causa de muerte en la población adulta en nuestro país (Figura 1).

Esta situación ha mejorado considerablemente en los últimos cincuenta años, gracias a la creación del Servicio Nacional de Salud el año 1952 y a la adopción por sucesivos gobiernos, desde entonces, de un Programa Nacional de Control de la Tuberculosis moderno y efectivo.

Chile alcanzó el llamado umbral de la etapa de eliminación de la tuberculosis, es decir una incidencia de casos nuevos inferior a 20 por 100.00 habitantes, en el año 2000 (Figura 2). Actualmente esta tasa es inferior a 13/100.000, lo que contrasta muy favorablemente con un promedio mundial estimado más de 10 veces superior (138/100.000).Sin embargo, hay que señalar que en Chile aparecen cada año más de 2.000 casos

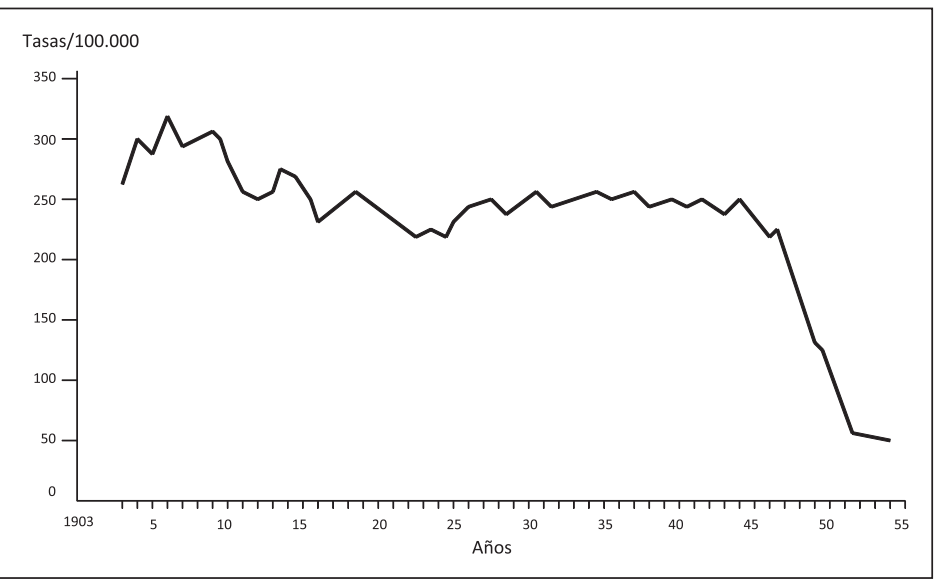

Figura 1. Mortalidad por tuberculosis. Chile 1903 -1955.

Rev Chil Enf Respir 2011; 27: 161-168 


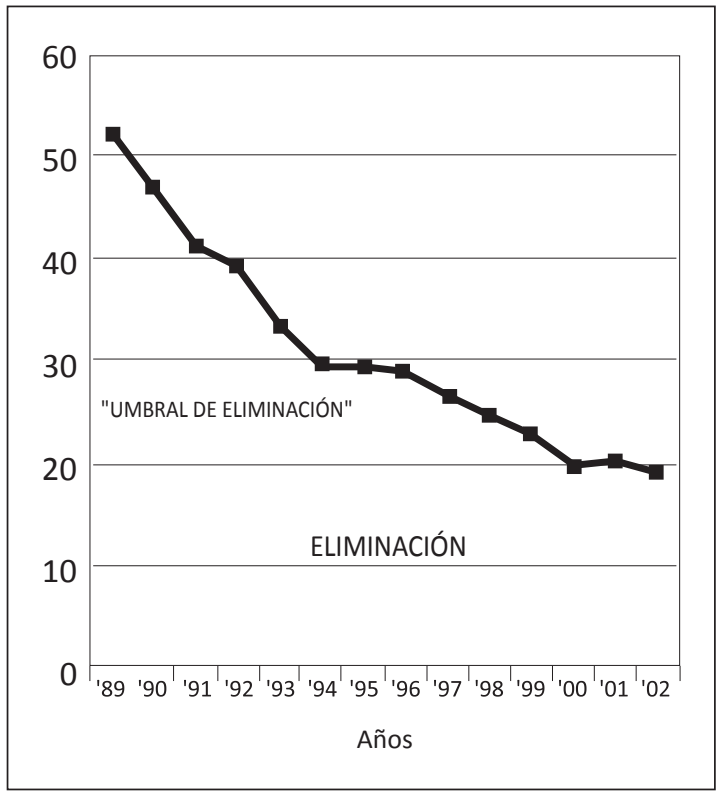

Figura 2. Morbilidad de la tuberculosis. Chile. 1993 a 2002.

nuevos de tuberculosis, es decir 7 enfermos en promedio diariamente y fallecen más de 200 de ellos, es decir 5 de nuestros ciudadanos mueren cada semana de una enfermedad totalmente curable como es la tuberculosis y nadie se da por enterado. Es de imaginar qué sucedería si falleciera una sola persona por semana por virus Hanta.

El Ministerio de Salud de Chile ha fijado las siguientes metas enfocadas a la eliminación de la tuberculosis en nuestro país: La primera, la de lograr una tasa inferior a 20/100.000, ya se cumplió el año 2000. La segunda, la de alcanzar la etapa de eliminación avanzada de la enfermedad (menos de 10/100.000) el año 2010, no se logró, pero estuvimos cerca. El gran desafío actual es alcanzar la etapa de eliminación de la tuberculosis como problema de salud pública, es decir menos 5 casos por 100.000 habitantes para el año 2020 . Pero, la erradicación, definida en términos epidemiológicos, como menos de 1 caso bacilífero por un millón de habitantes, aparece actualmente como una meta inalcanzable (Tabla 1). En realidad, no podemos hablar de verdadera erradicación hasta que fallezca el último portador de bacilos vivos, en fase latente, en el mundo. Esto no lo verá ninguno de los que lean este artículo.

Por otra parte, al ir disminuyendo, la tuberculosis se va concentrando alrededor de los casos contagiosos y en grupos especiales de mayor riesgo de padecerla.

En un interesante análisis epidemiológico sobre la incidencia de la tuberculosis en la Región
Metropolitana, el Dr. Christian García, Jefe del Programa Nacional de Control de la Tuberculosis de Chile, ha encontrado que en tanto la incidencia de esta enfermedad en Santiago, en 2008, fue de $14,2 / 100.000$ habitantes, hubo una serie de grupos de riesgo en los cuales fue considerablemente mayor: adultos mayores (32,8/100.000); extranjeros (37,5/100.000); contactos de pacientes con tuberculosis (104,5/100.000); reos (213,4/100.000); personas en situación de calle (218,7/100.000) y personas infectadas con VIH (380,5/100.000).

Por su mayor número, cabe destacar a los adultos mayores, que representan el $18,8 \%$ de las personas con tuberculosis en la región metropolitana.

A continuación daré algunas pinceladas sobre los que a mi juicio son los principales desafíos para lograr la eliminación de la tuberculosis en Chile y el mundo:

- Encontrar métodos de diagnóstico más eficaces;

- descubrir nuevas drogas de acción antituberculosa, que permitan abreviar el tratamiento de los casos nuevos y mejorar los esquemas de retratamiento para los enfermos multiresistentes;

- identificar a los portadores de infecciones latentes de alto riesgo de desarrollar tuberculosis, para someterlos a quimioprofilaxis;

- encontrar nuevas vacunas pre y pos infección, más eficaces que la BCG;

- enfrentar con más eficacia los nuevos desafíos que presentan las nuevas epidemias derivadas de la asociación TBC/SIDA y de las Tuberculosis multi-resistentes.

\section{Métodos de diagnóstico más eficaces, basados en las técnicas de la biología molecular}

Hasta ahora para el diagnóstico de la tuberculosis en Chile se ha empleado una estrategia de Salud Pública que permite, con la simple baciloscopia, aplicada a los consultantes espontáneos de los Servicios de Salud que tienen tos por más de 2 semanas, los llamados sintomáticos respiratorios, diagnosticar la mayoría de los casos avan-

Tabla 1. Programa enfocado en la eliminación

$\begin{aligned}<20 / 100.000 & \text { (umbral de la etapa de eliminación: } \\ & 2000) \\ <10 / 100.000 & \text { (Etapa de Eliminación Avanzada: } \\ & 2010) \\ <5 / 100.000 & \text { (Eliminación/Problema de Salud } \\ & \text { Pública: 2020) } \\ & \text { ¿ Erradicación } ?\end{aligned}$


zados de tuberculosis, que son los principales transmisores de la infección. Pero, en la etapa en que estamos ahora, es necesario entrar a una fase clínica, para intentar diagnosticar la enfermedad en etapas más tempranas (Tabla 2).

En los casos de tuberculosis menos avanzadas, en los niños y en las formas extra-pulmonares, tenemos que recurrir a los cultivos, que son más sensibles y específicos, pero que tienen el gran inconveniente de que demoran entre 4 y 8 semanas en demostrar el desarrollo micobacteriano. También hay que hacer más radiografías de tórax, recurrir a veces a procedimientos invasivos, y por fin desarrollar nuevos métodos de diagnóstico más sensibles que la baciloscopia y más rápidos que los cultivos.

Durante los últimos años ha ido apareciendo un gran número de métodos de diagnóstico de la tuberculosis más sensibles y efectivos. El actual desafío es implementarlos en nuestro medio, con un sentido de urgencia. Entre ellos se destacan (Tabla 3):

- Medios de cultivo líquidos, radiométricos o colorimétricos, que permiten la identificación de las distintas micobacterias en menos tiempo;

- También disponemos actualmente de sondas genéticas, mediante la tecnología de hibridación en tiras con sondas radioactivas o colorimétricas (Line Probe Assays-LIPAs).

- Técnicas de amplificación genética basadas en la reacción en cadena de la polimerasa (PCR) y sus numerosas variantes.

- Microarrays o microconjuntos. Expuesto en forma simple, basta disponer de los cerca de 4000 genes que tiene cualquier micobacteria, en una especie de tablero cuadriculado e hibridizarlos con una muestra en estudio, para detectar las diferencias entre ambas. Cuando los genes son complementarios, dan una colo-

Tabla 2. Diagnóstico de la tuberculosis

\begin{tabular}{|ll|}
\hline Fase de salud pública & Fase clínica \\
$\begin{array}{l}\text { En sintomáticos respira- } \\
\text { torios: } 2 \text { baciloscopías de } \\
\text { la expectoración }\end{array}$ & $\begin{array}{l}\text { En pacientes con baci- } \\
\text { loscopías negativas, en } \\
\text { tuberculosis infantil, y } \\
\text { en las tuberculosis extra- } \\
\text { pulmonares }\end{array}$ \\
$\begin{array}{l}\text { Permite diagnosticar } \\
\text { alrededor del 70\% de los } \\
\text { casos más contagiosos }\end{array}$ & $\begin{array}{l}\text { Más cultivos (BACTEC, } \\
\text { Más radiografías de tórax } \\
\text { Métodos más invasivos } \\
\text { Nuevos métodos diag- } \\
\text { nósticos }\end{array}$ \\
\hline
\end{tabular}

ración determinada; cuando en la muestra en estudio hay genes diferentes, éstos se revelan porque presentan otra coloración. De esta manera, se están identificando los genes del bacilo tuberculoso que determinan la transmisibilidad, otros la virulencia, aquellos de los cuales depende la latencia, etc. Así se van conociendo los antígenos más específicos para el desarrollo de nuevos métodos diagnósticos, los genes más vulnerables que pueden ser blanco de nuevas drogas y se están identificando los epítopes más inmunógenos para la generación de nuevas vacunas.

- Técnicas de la llamada Epidemiología Molecular, basadas inicialmente en el análisis de los Fragmentos de Restricción de Longitud Polimorfa (conocidos como RFLP, según las siglas anglosajonas), que permiten identificar las llamadas "huellas dactilares" o "fingerprinting" de muchas enfermedades y condiciones, y que en tuberculosis permiten identificar las distintas cepas micobacterianas, lo que es de gran utilidad para el estudio de micro-epidemias. En la Figura 3 se grafica un estudio de RFLP obtenido de aislados clínicos en Madrid, España, que muestra dos patrones RFLP idénticos, que representan un "cluster" como expresión de una transmisión reciente.

Pero, lo más urgente es encontrar métodos no sólo más sensibles que la baciloscopia, sino también más simples, rápidos y económicos, que puedan ser empleados por médicos generales en el llamado punto del diagnóstico. Uno de los más promisorios, que está siendo propiciado actualmente por la OMS es el llamado Xpert MTB/RIF, una técnica de amplificación genética que a través de la medición automática del ADN micobacteriano permite hacer el diagnóstico de tuberculosis y de multi-resistencia en el terreno, en pocos minutos, a un costo inicial del equipo de 17.000 dólares. Debemos conocerla bien porque ya se está ensayando también en el diagnóstico de diversas infecciones virales como la influenza y para el

Tabla 3. Nuevas técnicas diagnósticas

- Medios de cultivo líquidos (BACTEC y MGIT)
- Sondas genéticas. Line Probe Assays (LIPAs)
- Técnicas amplificación genética (PCR, LCR, SDA,
TMA)
- Microarrays (Microarreglos o Microconjuntos)
- Técnicas de la Epidemiología Molecular (RFLP)




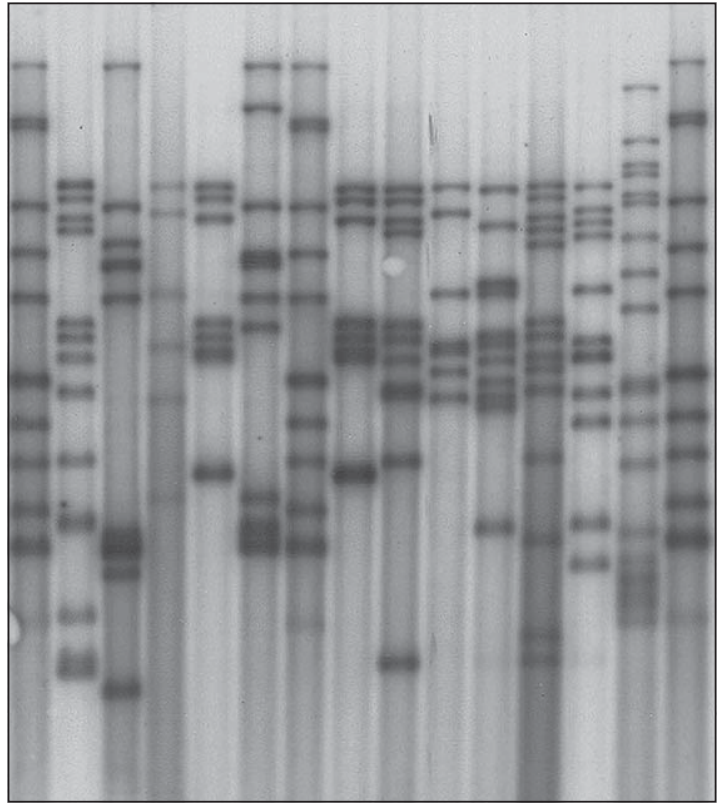

Figura 3. Huellas de ADN con IS6110 (patrones RFLP) de aislados clínicos de $M$. tuberculosis de Madrid.

diagnóstico de infecciones multi-resistentes estafilocócicas, por pseudomonas y otras (Figura 4).

En breve, el Xpert MTB/RIF es un test automatizado para el diagnóstico de tuberculosis basado en la detección de ácidos nucleicos con cartuchos. Simplifica la detección molecular integrando y automatizando los tres procesos requeridos para pruebas nucleares basadas en PCR: Extracción de ADN; amplificación y detección. Supera la complejidad de las pruebas nucleares, el riesgo de contaminación cruzada y las limitaciones de bioseguridad. Detecta la presencia de Мyсоbacterium tuberculosis y, además, resistencia a la rifampicina directamente en una muestra de expectoración. Y, lo que es aún más importante produce resultados en menos de 100 minutos.

Tratamientos más breves, lo que depende del desarrollo de nuevas drogas antituberculosas

El tratamiento actual de la tuberculosis basado en la asociación de isoniacida, rifampicina, pirazinamida y etambutol, ha sido considerado como el mayor avance de la medicina de mediados del siglo XX (Tabla 4). Sin embargo, aunque se le ha bautizado como "Short Course",es aún demasiado prolongado. El desafío actual es encontrar nuevas drogas que permitan abreviarlo a 4 meses o menos y que, además, ayuden a controlar las nuevas epidemias de tuberculosis multi-resistentes.

Chile fue el primer país del mundo que insistió en la importancia de supervisar la administración de los tratamientos antituberculosos dentro de un Programa Nacional de Control de la Tuberculosis. Este concepto revolucionario, que se denomina actualmente Tratamiento bajo Observación Directa o DOT, según sus siglas en inglés, se descubrió e inició en el Hospital San Juan de Dios de Santiago. Durante muchos años predicamos que la tuberculosis era una enfermedad $100 \%$ curable siempre que se respetaran 3 principios fundamentales. Los tratamientos debían ser asociados, para evitar el desarrollo de resistencia bacteriana; debían ser prolongados, para evitar las recaídas y,

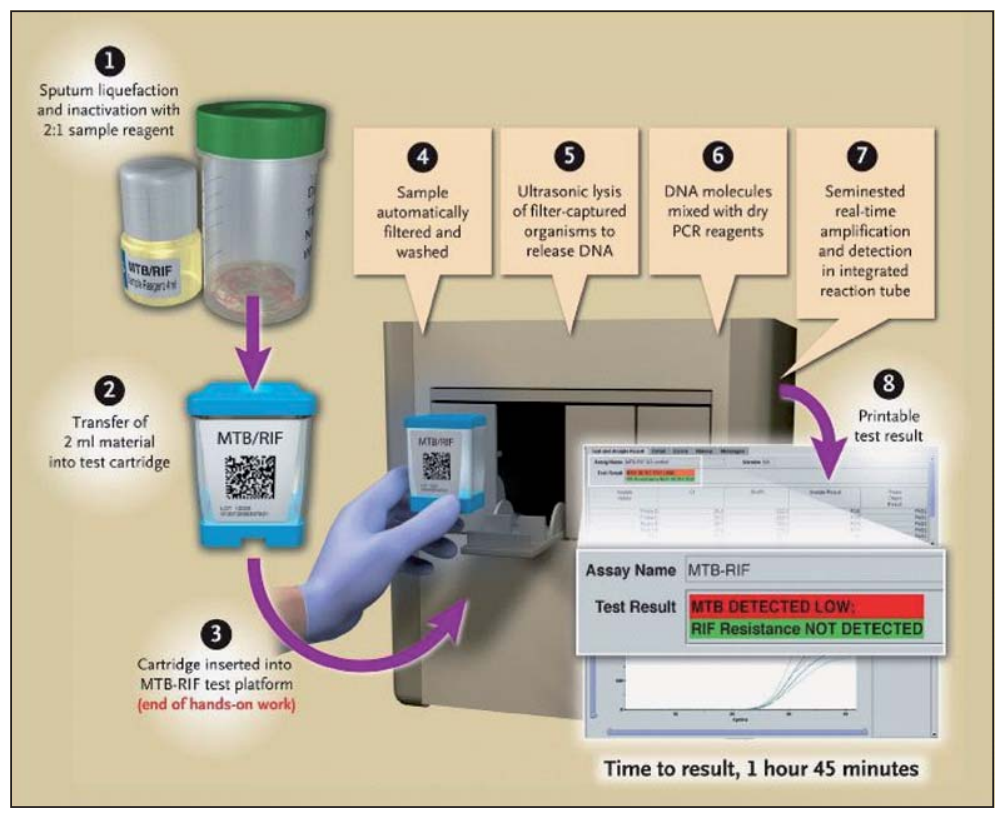

Figura 4. Xpert MTB/RIF. 
Tabla 4. Tratamiento de la tuberculosis

\begin{tabular}{|lcc|}
\hline $\begin{array}{l}\text { Drogas } \\
\text { (mg) }\end{array}$ & $\begin{array}{c}\text { Fase diaria } \\
\mathbf{5 0} \text { dosis - } \mathbf{2} \text { meses } \\
\mathbf{4 0} \mathbf{- 5 9} \mathbf{~ k g}\end{array}$ & $\begin{array}{c}\text { Fase bisemanal } \\
\mathbf{3 2} \text { dosis - } \\
\text { meses }\end{array}$ \\
\hline Isoniacida & 300 & 800 \\
\hline Rifampicina & 600 & 600 \\
\hline Pirazinamida & 1.500 & \\
\hline Etambutol & 1.200 & \\
\hline
\end{tabular}

En enfermos con peso corporal inferior a $40 \mathrm{~kg}$ o superior a $60 \mathrm{~kg}$ deberán ajustarse las dosis por $\mathrm{kg}$ de peso.

por fin, debían ser administrados bajo supervisión directa de personal de salud especialmente entrenado, para asegurarse que los enfermos realmente se los tomaran.

Aun con todas estas medidas, la tuberculosis sólo es 100\% curable en los enfermos que completan su tratamiento regularmente, pero, pero en la práctica existen dos grandes limitaciones: los enfermos que mueren durante el tratamiento, generalmente por lo tardío de su diagnóstico, y los que lo abandonan antes de completarlo. Esto explica que pocos países hayan alcanzado la meta de la OMS de curar más del 85\% de los casos diagnosticados (Figura 5).

Afortunadamente actualmente se dispone de 10 nuevos medicamentos muy interesantes en distintas fases de desarrollo. Los más avanzados son agentes antimicrobianos de grupos farmacológicos similares a los ya conocidos, que ya están en fase II y III de investigación, como la rifapentina, derivada de las rifamicinas, y las nuevas generaciones de fluoroquinolonas (levofloxacina, moxifloxacina y gatifloxacina). Otros compuestos prometedores, en distintas etapas de

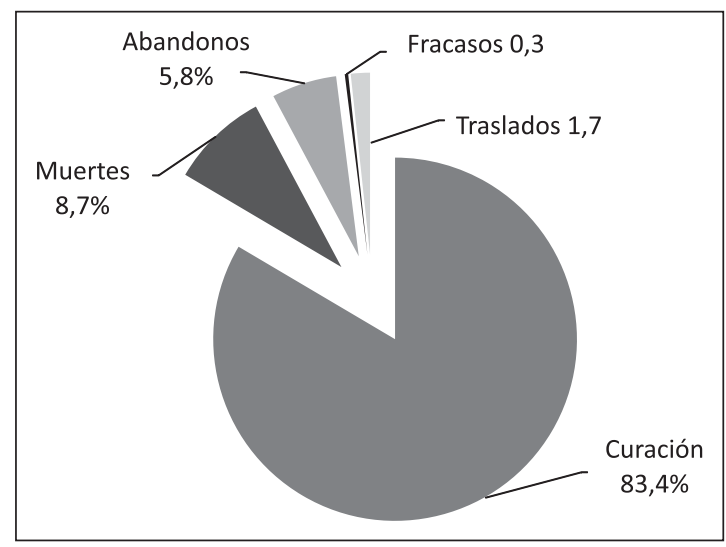

Figura 5. Resultados del tratamiento de la tuberculosis (cohorte 1998 - 2009. Chile).
Tabla 5. Nuevas drogas antituberculosas

- Nuevas rifamicinas (rifabutina, rifapentina, rifalazid)
- Nuevas quinolonas (levofloxacina, moxifloxacina,
gatifloxacina)
- Diarylquinolinas (TMC207)
- Oxazolidinonas (linezolid, PNU-100480, AZT-5847)
- Nitroimidazoles (PA824, OPC-67683)
- Pyrroles (LL3858)
- Diaminas (SQ109)

investigación, son los derivados de las oxazolidinonas (linezolid, PNU 100480, AZT-5847), los nitroimidazoles (PA824, OPC-67683), los pirroles (LL3858), las diarylquinolinas (TMC207) y las diaminas (SQ109) (Tabla 5).

Se espera que la asociación de algunos de estos nuevos fármacos, con los ya conocidos, permita enfrentar el nuevo desafío de las tuberculosis multi-resistentes y, eventualmente, abreviar el tratamiento de todas las formas de la enfermedad. Algunos de estos medicamentos, también parecen tener acción contra los bacilos latentes, principal causa de la reactivación de la tuberculosis, como veremos a continuación.

\section{Tratamiento de la infección latente. Nuevos métodos para diagnosticarla}

Porque, aunque lográramos diagnosticar hoy todos los enfermos contagiosos y los curáramos a todos con nuestros modernos tratamientos, seguirían ocurriendo casos de tuberculosis hasta bien entrado este siglo a partir de los pacientes infectados que tienen bacilos vivos, aunque en fase latente, pero que pueden reactivarse ante cualquier disminución de su inmunidad. Por esto, en esta etapa, una nueva estrategia es la quimioprofilaxis con isoniacida en los grupos de individuos de alto riesgo de hacer tuberculosis; pero, para poder aplicar esta intervención es necesario identificarlos. Hasta hace poco sólo podíamos hacerlo con la reacción de tuberculina, es decir del PPD, técnica que adolece de numerosas limitaciones.

Para identificar a los sujetos infectados con el $M$. tuberculosis, disponemos actualmente de métodos más sensibles y sobre todo más específicos que el PPD, llamados IGRAs, derivados de la medición de interferon gama liberado por la sangre de un individuo, cuando en el pasado ha sido sensibilizado con las tubérculo-proteínas del bacilo de Koch. Las técnicas más empleadas hasta ahora, son el Quantiferon TB-Gold y el ELISPOT. Ambas utilizan el ESAT 6 y CPF 10, dos 
antígenos que son específicos del M. tuberculosis, por lo que no dan reacciones positivas cruzadas en los vacunados con BCG. En la actualidad sólo están disponibles en algunas clínicas privadas de Santiago. Han pasado los tiempos heroicos del Servicio Nacional de Salud, cuando la tecnología médica más avanzada sólo estaba disponible en los hospitales públicos.

\section{Nuevas vacunas. Necesitamos nuevas vacunas más eficaces que la BCG}

Miles de investigadores están dedicando sus vidas a la búsqueda de una vacuna antituberculosa más efectiva que la BCG, que sea capaz no sólo de prevenir la infección tuberculosa (pre-exposición), sino también de reforzar la inmunidad de los ya infectados y aún de los enfermos (posexposición). Esta vacuna, que ya está en etapa de aplicación en el terreno, tornaría obsoletas la mayoría de las estrategias actuales para el control de la enfermedad y representaría un gran avance en el desarrollo de nuevas inmunizaciones contra otras enfermedades infecciosas, como el SIDA.

Con este fin, se están estudiando los antígenos más inmunógenos del bacilo tuberculoso o partes de él o de su ADN, el empleo de vacunas polivalentes, por introducción dentro del genoma de la vacuna BCG de epítopes de otros agentes infecciosos, y otras vías de administración de la vacuna BCG, como la inhalatoria, para aprovechar la conocida compartamentalización de la respuesta inmune. Actualmente hay en estudio 12 vacunas antituberculosas, en distintas fases de investigación. Dos de ellas ya entraron a la fase III y se están empleando en África.

Se ha planteado que una especie de vacuna BCG polivalente, a la cual se le hayan introducido genes más específicos de $M$. tuberculosis y antígenos de otros agentes infecciosos podría, en un futuro tal vez no tan lejano, ser nebulizada en una sala de cine, de modo que mientras se proyecta nuestra película favorita, se esté inmunizando a grandes sectores de la población de todas las pestes que azotan a la humanidad.

\section{Nuevos desafíos. Pero han aparecido dos nuevos desafíos: la asociaciónTBC-SIDA y las epidemias de Tuberculosis Multi-resistentes (TB-MDR/XDR)}

El primer gran desafío, que se manifestó a fines del siglo pasado, cuando la tuberculosis estaba iniciando un lento descenso en la mayoría de los países del mundo, fue la irrupción del virus de la inmunodeficiencia humana, que compromete preferentemente a los linfocitos CD4, que son los que nos defienden de las infecciones intracelulares como la tuberculosis. La aparición de esta nueva epidemia ha obligado a hacer una serie de cambios en la prevención, diagnóstico y tratamiento de la tuberculosis, cuando ésta se asocia al SIDA.

Por otra parte, frecuentemente se plantea el diagnóstico diferencial entre tuberculosis y micobacteriosis, o sea de enfermedades no tuberculosas producidas por micobacterias ambientales que se han hecho patógenas para el hombre. Esto está estimulando el desarrollo de nuevas técnicas de identificación de las distintas especies micobacterianas.

Además, ahora nos enfrentamos con la llamada Tercera Epidemia, la de las Tuberculosis Multiresistentes, que hizo su aparición a fines de siglo pasado en Sud-África unida a la epidemia de SIDA, con una letalidad cercana al 100\%. Pero, en realidad, son muchas las distintas miniepidemias de tuberculosis multi-resistente que están ocurriendo en todo el mundo.

En primer lugar existe la Tuberculosis MultiDrogo-Resistente (TB-MDR), resistente por lo menos a isoniacida y rifampicina, las dos drogas de acción antituberculosa más potente de que disponemos; después la Tuberculosis Extensamente-Drogo-Resistente (TB-XDR), que además es resistente a los fármacos antituberculosos de segunda línea más eficaces: las fluoroquinolonas y los inyectables (kanamicina, amikacina y capreomicina), y por fin, la Tuberculosis Totalmente Resistente (TB-XXDR), que puede llegar a ser resistente a todos o casi todos los medicamentos antituberculosos (Tabla 6).

Estas nuevas epidemias se deben a la mala utilización que se ha hecho en muchos países de la quimioterapia, dado que los malos tratamientos y sobre todo las fallas en la supervisión de ellos, favorecen la selección de cepas naturalmente resistentes a todas las drogas antituberculosas que existen en toda población bacteriana numerosa.

Tabla 6. Tuberculosis multi-resistentes

1. TB-MDR. Tuberculosis Multi - Drogo-Resistente: Resistente por lo menos a Isoniacida y Rifampicina

2. TB-XDR. Tuberculosis Extensamente Resistente:

- Resistente a Isoniacida y Rifampicina y, además, resistente a alguna Quinolona y a algún inyectable (Kanamicina, Amikacina o Capreomicina)

3. TB-XXDR. Tuberculosis Totalmente Resistente: Resistente a todos o casi todos los fármacos antituberculosos de primera y segunda línea 
Posteriormente, la OMS ha hecho varias encuestas internacionales para monitorizar la magnitud y evolución de esta nueva epidemia, la última de las cuales mostró que ya el 3\% de los casos nuevos diagnosticados a nivel mundial son portadores de cepas multi-resistentes. Pero esto no da una idea adecuada de la gravedad del problema, porque esta cifra es superior al 10\% en algunos países, incluyendo algunos de nuestra América.

Lo más grave es que los enfermos portadores de cepas multi-resistentes adquiridas contagian a sus contactos y al resto de la población sana con sus mortíferas cepas. Y es así como la OMS ha calculado que actualmente existen en el mundo más de 50 millones de individuos infectados con cepas multi-resistentes.

En Chile, debido al énfasis en los tratamientos estrictamente supervisados, sólo tenemos el desarrollo de pocos casos anuales de TB MDR, pero es necesario mantener y extremar todas las medidas de control actuales..

Disponemos actualmente de tratamientos adecuados para intentar curar estos pacientes, aunque a expensas de asociaciones de drogas más caras, más tóxicas y menos efectivas, que obligan a prolongarlos por 18 a 24 meses. Pero, antes de intentar curar estos infortunados enfermos, es necesario diagnosticar oportunamente su condición de multi-resistentes. Para ello están en desarrollo nuevos estudios de sensibilidad, fenotípicos y genotípicos, frente a las distintas drogas antituberculosas. Pero, casi todos ellos dependen de cultivos que requieren demasiado tiempo para su desarrollo e identificación.

Se ha visto que la resistencia a la rifampicina es un marcador de multi-resistencia, porque casi siempre se acompaña de resistencia a isoniacida. Afortunadamente la resistencia a este fármaco se concentra en un pequeño segmento del gen del Mycobacterium tuberculosis, de modo que el diagnóstico de multi-resistencia se puede inferir fácilmente con el estudio de los polimorfismos del gen rpo B en cultivos micobacterianos. Afortunadamente, esta determinación promete sim- plificarse notablemente con el empleo del Xpert $M T B / R I F$, en muestras directas de esputo (fig. 4).

Los nuevos desafíos que enfrenta el control de la tuberculosis son numerosos. Pero, como nunca antes, contamos ahora con nuevas y más eficientes tecnologías. El gran desafío actual es ponerlas al alcance de todos los países. Sólo si llegamos a disponer de ellas en nuestro medio y somos capaces de aplicarlas bien, estaremos en condiciones de alcanzar la conquista de la tuberculosis en el curso de una generación.

\section{Bibliografía}

1.- GARCÍA C. Tuberculosis en grupos de riesgo en la Región Metropolitana. 2008. Rev Chil Enf Respir 2011; 26: 105-11.

2.- FARGA V , CAMINERO J A. Tuberculosis. Tercera Edición. Editorial Mediterráneo. 2010.

3.- ZÚÑ̃IGA M. La eliminación de la tuberculosis como problema de salud pública. Situación de Chile en el año 2008. Rev Chil Enf Respir 2009; 24: 117-26.

4.- FARGA V. La conquista de la tuberculosis. Rev Chil Enf Respir 2004 20:101-8.

5.- WORLD HEALTH ORGANIZATION. Global Tuberculosis Control. WHO Report 2009.WHO/HTM/ TB/2009.411.

6.- DORMAN S E. New diagnostic tests for tuberculosis: Bench, bedside, and beyond. Clin Infect Dis 2010; (50 Suppl 3): 17S-77S.

7.- MA Z, LIENHARDT C, MCILLERON H, NUNN A J, WANG X. Global Tuberculosis drug development pipeline: the need and the reality. Lancet 2010; 375: 2100-9.

8.- Centers of Disease Control and Prevention. Updated guidelines for using interferon gamma release assays to detect Mycobacterium Tuberculosis infection. MMWR 2010; 59 (RR-5): 1-26.

9.- KAUFMANN S H, HUSSEY G, LAMBERT P H. New vaccines for tuberculosis. Lancet 2010; 375: 2110-19.

10.- SWAMINATHAN S, PADMAPRIYADARSINI C, NARENDRAN G. HIV-associated tuberculosis. Clinical update. Cl Infect Dis 2010; 50: 1377-86.

11.- CAMINERO J A. Multidrug-resistant tuberculosis: Epidemiology, risk factors and case-finding. Intl J Tuberc Lung Dis 2010; 14: 382-90.

Correspondencia a:

Dr. Victorino Farga C.

Providencia 2608, piso 3. Santiago, Chile.

E-mail:vfarga@gmail.com 